\title{
THE REAL RISK-RATE OF DEATH TO MOTHERS FROM CAUSES CONNECTED WITH CHILDBIRTH.*
}

\author{
BY WILLIAM TRAVIS HOWARD, JR.
}

(Received for publication, January 4th, 1921.)

\author{
INTRODUCTTON.
}

It is a fair statement that few, if any, of those interested officially and unofficially in public health in the cities and states of this country have any really intelligent appreciation of the high fatality risks of pregnancy and of delivery from that state. Seriously thoughtful consideration of these subjects is almost entirely confined to a few leading obstetricians, whose warnings and teachings only too often fall upon deaf ears. With the exception of these and of some of the more intelligent of those engaged in the infant welfare movement who have realized from practical experience, supported at times by figures not often dignifiable by the term statistics, that the reduction of infant mortality is to a large degree bound up with pre-natal, natal, and post-natal care of the mother, few in this country have any accurate conception of the risk run by the average woman in her lying-in. The great movements directed against puerperal infection since Semelweiss' discovery, Holmes' erusade, the exposure of the deadly obstetrical hospitals, the recognition of the bacterial causation of the disease, and the perfection of the anti- and a-septic methods exhausted themselves, after improving obstetrical hospitals, teaching, and nursing, in inadequate regulations of midwives. In the meantime, researches in obstetrics advanced knowledge in regard to the recognition and control of other causes of maternal mortality in the pregnant and lying-in states; such as, hemorrhage, intoxications, malformations and malpositions, rupture of the uterus, and the like, which, taken together, account for the larger moiety of maternal deaths. But, the relatively highly developed knowledge concerning practical obstetries is so meagerly diffused and so ineffectively applied to practice, that certainly in the registration area of the United States it is not brought

" Papers from the Department of Biometry and Vital Statistics, School of $\mathbf{H y}$ giene and Public Health, Johns Hopkins University, No. 26. 
to bear with sufficient force to prevent the occurrence of innumerable major and minor illnesses and a.large number of unnecessary maternal deaths.

One of the most important funetions of vital statisties is to determine accurately the risk of illness and of death of those actually exposed to a particular disease or disease group, or, in other words, to measure specifically the forces of morbidity and of mortality. The terms of the risks so determined are commonly expressed in ratios or rates indicating the proportions of the numbers affected to the num. bers exposed, and the real value of such rates must depend upon the accuracy and the comprehensiveness of the data in regard to both the affected and the exposed. It is only when the data include such essential qualities as age, sex, race stock, and occupation that the resulting rates may be regarded as satisfactorily specific. In actual experience, the data available to vital statisticians are, in general, so lacking in comprehensiveness in these respects, that there exists hardly a single example of an accurately defined rate expressed specifically in terms of risk on the part of those definitely exposed to illness or to death from a particular disease. In consequence, the public health official is seriously handicapped in defining his problems, in devising administrative measures, and in estimating their value. Likewise, the student of the natural history of disease must so often appeal in vain to the statistical method for aceurate measurement of the forses of morbidity and mortality and must remain content with rates relatively crude and subject to various adjustments in the process of being rendered specific for even one or two eategories. In measuring the force of mortality in affections of the puerperal state, it has been customary to use rates based on the number of maternal deaths in relation to (a) the whole population, (b) the whole number of females, (c) the number of females within the usual childbearing ages ( 15 to 45 years), or (d) the total number of labors as evidenced by the number of reported live births. Of these methods, the latter is obviously the only one that even approaches specificity; the others are, in the nature of things, necessarily so general and so wide of the mark that they are evidently useless for any serious attempt to estimate the force of mortality in a single community, or to compare it either in the same community over a term of years or in different communities. Riskrates calculated on the number of maternal deaths from causes connected with the puerperal state and the number of live births occurring within a given period are subject to two important sources of 
error. The number of live births, used here as the divisor, does not accurately measure the actual number of labors, i.e., the number of women exposed to death in childbearing; for some labors produce more than one living child, and stillbirths, which in some cases are dependent upon conditions that materially enhance maternal risks and which represent a variable but not inconsiderable number of labors, are left out of account.

It occurred to me in 1917 , when confronted with problems of this character in the Health Department of Baltimore, that by using the sum of the living and of the still births reported and the number of the deaths of mothers aseribed to puerperal affections, annual death rates might be obtained, expressing in specifie terms the actual risk of dying for women definitely exposed in childbearing. Stated in formal terms, the true puerperal risk-rate in childbearing would be derived from the formula:

$$
R P=\frac{D P}{B L+} \overline{B S},
$$

where $D P$ equals the number of maternal deaths due to causes definitely connected with the puerperal state and $B L$ and $B S$ equal the number of live and still births respectively.

Risk rates calculated on this basis for the total deaths in the puerperal state and for the deaths under the different rubrics 134 to 141 , inclusive, of the international classification of the causes of death, separately and in various combinations, on the data of the Baltimore Health Department for 1915 to 1917, gave interesting tables. Owing to inability to find data of sufficient value on which to base comparative studies-the Reports of the Registrar-General of England and Wales and the Birth Reports of the United States Census for the birth registration area being silent on stillbirths-the matter was dropped for the time. Recently, on becoming interested in the subject again, it oceurred to me that by utilizing the data of several large American cities, in which it might be assumed that the reports of live and still births and the reporting and classification of deaths are reasonably accurate, figures sufficiently large to eliminate chance and probable errors might be obtained. For this purpose, New York, Philadelphia, Boston, and Baltimore were chosen for the five year period 1915 and 1919 , and, as will be pointed out later, there is a remarkably close correspondence in the rates obtained, and the rates calculated from the figures of these cities seem to afford a fairly accurate criterion of the risk-rate of death applying to childbearing in women in these 
particular urban communities. Fortunately for purposes of comparison of the value of the method and investigation of the whole subject on a broader scale in this eountry, the report for 1918 of the Bureau of the Census on births within the registration area includes stillbirths, and this large material is now available for the first time for such uses.

Before discussing the results of this inquiry, it is necessary to point out that on looking further into the question, I found that in the idea of taking stillbirths into consideration I was anticipated by Dr. William Farr, at least. Deeply interested in this subject from a date early in his connection with the Registrar-General's Office (discussing this subject first in the Fifth Annual Report, 1843), he dealt with it fully in the Seventeenth Annual Report in 1856, when he utilized the data of the eight year period 1847 to 1854 , which he expressed in tables of rates obtained by diving the material deaths by the total number of live born children. But he clearly recognized, that, as the term Births, as used in the returns, expressed only the number of children born alive and not the exact number of childbearings or accouchements, to ascertain the true danger of childbirth to mothers, it was necessary to take into account not only the reported live births, but stillbirths and plural births. Correction for plural births on the basis of the returns for 1852 indicated the necessity of a reduction of about 1 per cent. from the number of reported births, and correction (based on some French figures) for stillbirths required the addition of about 3 per cent; so it would appear that if something like 2.5 per cent. be added to the number of reported live births, the sum would indicate with some degree of accuracy the actual number of childbearings. He concluded that "on an average of eight years ( 1847 to 1854 ), to every 10,000 children born alive 54 mothers died; so about 53 in every 10,000 or 1 in 189 accouchments were fatal." Farr elassed puerperal deaths under metria-the term adopted for puerperal infection in his statistical nosology-and all other causes. In the same article, he presented the following table, showing the mortality per 100,000 childbearings of women of different ages:

TABLE I.

\begin{tabular}{|c|c|c|c|}
\hline Ages of women. & Total deaths. & Deathe by metria. & $\begin{array}{l}\text { Deaths by other } \\
\text { accidenta. }\end{array}$ \\
\hline 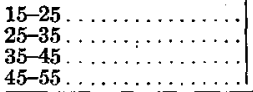 & $\begin{array}{l}668 \\
425 \\
633 \\
883\end{array}$ & $\begin{array}{l}277 \\
148 \\
154 \\
163\end{array}$ & $\begin{array}{l}391 \\
277 \\
479 \\
720\end{array}$ \\
\hline
\end{tabular}


Commenting on this table, Farr pointed ont that the mortality in childbearing is least during the age period 25 to 35 -when more than half of the children are borne by their mothers-and that as the rates of mortality in the last three age periods are in nearly the ascending ratio as 2,3 , and 4 , the calamitous deaths of mothers in childbed are governed by a mathematical law. He further estimated that the death rates for women from all causes for these age periods were raised by childbearing risks per 100 as follows :

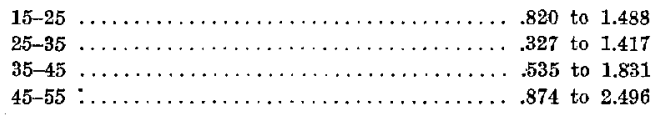

In the Thirty-third Annual Report in 1870, Farr, replying to the criticisms of Mathews Dunean, demonstrated that the returns to the Registrar-General were reasonably complete and that the figures nsed by him included deaths only in childbearing and excluded deaths due to other causes but occurring in pregnant or ehildbearing women; i.e., that the classification was designed to show the actual causes of death. Among other things, Farr showed that in eleven large English towns the ehildbearing mortality was 4.9 and in sixty-four healthy country districts, 4.3 per 1,000 .

Returning again to the subject, in the Thirty-ninth Annual Report of 1876 , Farr pointed out that in the thirty years between 1847 and $1876,106,565$ mothers died in England in childbirth, or about 5 in every 1,000 or 1 to every 200 children born alive. The proportions varied from year to year, the lowest per 10,000 live born children being 42 in 1857 and the highest, 69 in 1874. In 1876 it was 47.

\section{TABLE II.}

Maternal death rates 10,000 live births from causes connected with the puerpera? state, in England and Wales, 1847-1876, together with the percentage contributed by each separate cause to the whole number of such deaths.

(Condensed from the table of Dr. William Farr, Thirty-ninth Annual Report of the Registrar-General, 1876, page 279.)

\begin{tabular}{|c|c|c|c|c|c|c|c|c|c|}
\hline \multirow[b]{2}{*}{$\begin{array}{l}\text { 1847-1876, } \\
\text { inclusive. }\end{array}$} & \multirow[b]{2}{*}{ Living births. } & \multicolumn{3}{|c|}{ Aceidents of child birth. } & \multicolumn{3}{|c|}{ Metria. } & \multicolumn{2}{|c|}{$\begin{array}{l}\text { Metria and ehild } \\
\text { birth. }\end{array}$} \\
\hline & & Deaths. & $\begin{array}{c}\text { Rate } \\
\text { per } \\
10,000 \\
\text { birtba. }\end{array}$ & $\begin{array}{c}\text { Per } \\
\text { cent. } \\
\text { total } \\
\text { metria } \\
\text { and } \\
\text { child } \\
\text { birth. }\end{array}$ & Deaths. & $\begin{array}{c}\text { Rate } \\
\text { per } \\
10,000 \\
\text { birthe. }\end{array}$ & $\begin{array}{c}\text { Per } \\
\text { cent. } \\
\text { total } \\
\text { metrig } \\
\text { and } \\
\text { child } \\
\text { birth. }\end{array}$ & Deaths. & $\begin{array}{c}\text { Rate } \\
\text { per } \\
10, \text {,oo } \\
\text { Births }\end{array}$ \\
\hline Total. & $21,292,995$ & 68,241 & 32.05 & 64.04 & 38,324 & 18.00 & 35.96 & 106,565 & 50.05 \\
\hline
\end{tabular}


WILLIAM TRAVIS HOWARD, JR,

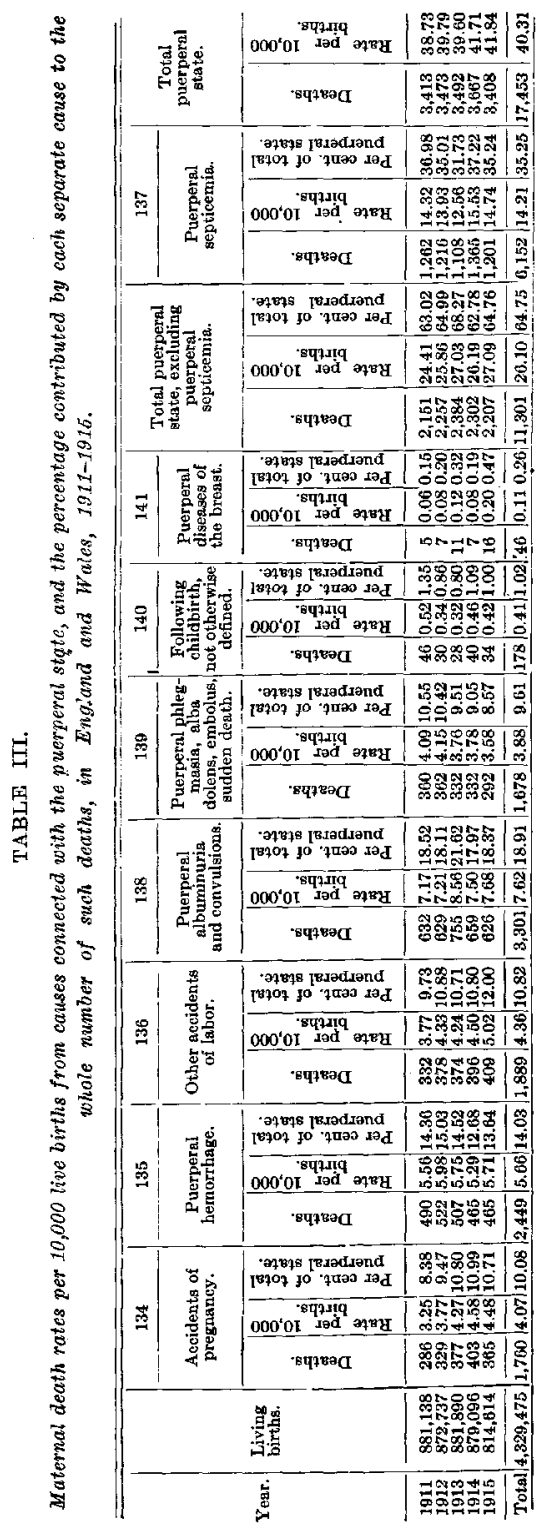


Table II is condensed from Farr's table of the annual mortality rates for this thirty year period as given on page 249 of the Thirtyninth Annual Report.

Farr blamed the high mortality of childbearing upon the poorly trained midwives, for in the experience of the Royal Maternity Charity, with two physicians and twenty-two trained and supervised midwives, of 9,019 deliveries of women in their homes during the three year period 1875 to 1877 there were lost only 21 women or 2.33 per 1,000 deliveries. The Birmingham Lying-in-Charity, in 8,607 deliveries, had a maternal mortality of 2.32 per 1,000 . In 4,390 deliveries at Canterbury, Mr. Ridgen lost only 2.05 mothers per 1,000.

For comparison with the foregoing and with tables for the United States which follow, the subjoined table is presented, giving the mortality in childbirth per 10,000 living children, both total and under the rubries 134-141, inclusive, of the international classification of the causes of death, for England and Wales for the five year period 1911 to 1915 , as stated in the annual reports of the Registrar-General (see Table III).

The annual reports of the Registrar-General for England and Wales still carry rates of childbed mortality calculated on the basis of ehildren reported born alive.

From the Swedish figures, notable for the eare and accuracy with which they have been collected since 1746 , Hendriks (1) has calculated rates showing the proportion of maternal deaths in childhood to women delivered, from 1776 to 1855 , from which Table IV has been constructed.

TABLE IV.

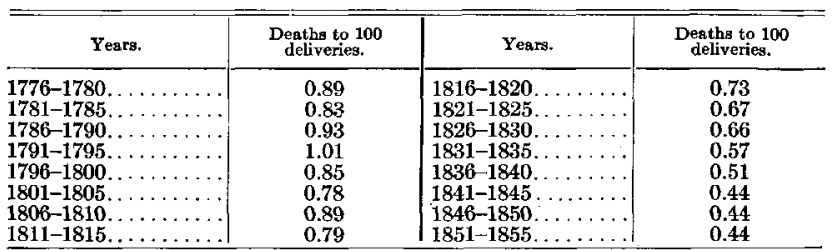

It would appear by inference to be probable, though he does not so state; that in arriving at his figures for "women delivered," Hendriks made allowances for plural and for still births.

The writings of Mathews Duncan and of various other obstetrieal 
writers on this subject may for the present purpose be dismissed as being based upon data of questionable accuracy, or of selected material or, of insufficient numbers. Some of the material is of value, however; as, for instance, that from certain lying-in charities and private practitioners, of which those quoted from Farr will serve as examples, for account is taken of the total number of deliveries and the maternal fatalities are presumably limited to those associated with labor.

The recent interesting article of Dublin (2), in which are compared the deaths from pnerperal diseases oceurring among a selected but large group of women insured in an industrial insurance company, with similar deaths among women in the registration area of the United States, has only an indirect bearing upon the questions under consideration, for the calculations are based upon the number of "females of the childbearing ages, namely, fifteen to forty-four."

However, none of the rates above considered are specific in the sense that they indicate with certainty the actual danger of childbearing, and to determine their real significance it is necessary to analyze the factors entering into both divisor and dividend. If the divisor embraced only the sum of the living and still births actually occurring, it would, when corrected for the number of plural births, represent the total number of pregnancies, which, developing to or near to the period of viability, eventuate in natural or artificially induced labor. Since the births of fetuses in the earlier months of pregnancy are not included, the total number of conceptions is not measured. Therefore, such figures are applicable not for determining' the risk to life involved in becoming pregnant, but for ascertaining the risk run by those pregnant women who bear either live children or "stillborn" children. Hence, it is essential to establish just what the term stillborn defines.

In the Report of the Bureau of the Census on Birth Statistics for the Birth Registration Area of the United States, for 1918, it is pointed out (pages 28 and 29) that the data relating to stillbirths must be interpreted with caution. Since the term stillbirth is not used in the same sense in the various states, the percentage of completeness of these reports is not known. The "model law" reads: "A stillborn child shall be registered as a birth and also as a death ... provided that a certificate of birth and a certificate of death shall not be required for a child that has not advanced to the fifth month of uterogestation." Minnesota, New York, and North Carolina have similar provisions ; the District of Columbia requires a certificate for a fetus 
"passed the fifth month"; the Indiana law reads "seven months gestation and over" ; and the remaining states use the term stillbirth without defining it. Since Maryland makes especial efforts to secure uniform registration of stillbirths of even the earlier months of uterogestation, the data for this state are not considered comparable with those of other states. It is held, however, that, since the figures of those states requiring reports only of children who have reached the fifth month approximate the figures of those states which do not define the term stillbirth, the conclusion is warranted that in the latter states only the stillbirths of the later months are for the most part reported; therefore, the figures are probably comparable. It is argued that the stillbirths of the later months of gestation must be well reported, because such stillbirths are interred, and burial cannot legally take place without a burial permit issued upon a physician's certificate. The data relating to stillbirths were compiled from transcripts of stillbirths reported as births, which has certainly resulted in figures smaller than would have been obtained had the transeripts of stillbirths reported as deaths been used.

Under the terms above outlined, stillbirths include some fetuses born dead before the period of viability. Since some physicians and midwives, in a small but not aceurately known proportion of instances, do return as stillbirths the births of embryos of less than the fifth month of gestation, and others neglect to report the birth of some fetuses advanced beyond the fifth month and born dead, it is probably a fair assumption that these two factors balance each other, and consequently that the number of instances of stillbirths so reported represent a fair approximation of the actual number of fetuses of five months and over of utero-gestation born dead, in the birth registration area as a whole.

The number of living births reported does not, of course, in all, or perhaps in any, of the divisions of this registration area, represent the whole number of children born alive, for the reporting of live births is probably nowhere in the United States absolutely accurate. On the basis of the figures for plural and single births (both live and still) as given in the Report of the Bureau of the Census on Birth Statistics for 1918, the proportion of the former to the latter is as 1.15 to 100 , or approximately 1 per cent.- the same percentage found by Farr for England and Wales, in 1852. It would, therefore, tend rather to decrease than to add to accuracy, to attempt to correct the figures for live births by counting the birth products of each plural 
pregnancy as a single unit. Attention must be called to two additional factors, the value of which is not in the present state of knowledge exactly ponderable--there must be greater risk involved in the parturient act for two or more children than for one, even should it be found that multiple pregnancy does not in itself involve greater danger to the mother than single pregnancy; and, no allowance is made for the difference in the danger between first and sueceeding pregnancies. The birth rate, i.e., the rate of reported live births per 1,000 total living population, for the whole birth registration area was 24.4 in 1918, a figure, which, when compared with New York City (23.51 for 1918) where the birth registration is known to be exeeptionally complete, would signify that the registration of births in the registration area is fairly accurate.

With these explanations and reservations, it may be concluded that the sum of the reported live and still births, as compiled by the Burean of the Census, furnishes a fairly accurate, though not an absolutely correct, estimate of the total number of single labors occurring among women five months pregnant and over, in the birth registration area during 1918.

The dividend includes all the deaths classified under rubries 134 to 141 , inclusive, of the international classification of the eauses of death, occurring in the cities and rural districts of the states of the birth registration area. Except where otherwise stated (in the case of certain eities in Tables VIII, IX, X, XI, XII, and XIII), the figures were obtained from the Mortality Statistics of the Bureau of the Census for 1918, which, in turn are compiled in the Bureau of the Census from transcripts of the original death certificates returned to local registrars. The classification of the deaths under the various rubries may thus be considered as done with consistency for the whole registration area, after the certificates have been subjected to a double scrutiny to provide against error frandulent or otherwise. Throughout this classification, as in that of the English tables, the deaths are classified specifically. Deaths of childbearing women due to other and ordinary causes are excluded ; for example, deaths of childbearing women from influenza, phthisis, heart disease, cancer, etc., are classified under the appropriate primary cause-the childbearing state being reckoned a secondary eause. The influenza epidemic of 1918 , therefore, had no appreciable influence upon the number of deaths classified as due to childbirth. As they stand, however, neither the total figures nor those under the separate rubrics can be aceepted 
as representing accurately the deaths occurring in women bearing children of five months fetation and over, since these figures represent the recorded deaths of women dying in any part of the pregnant state from causes conneeted speeifically with that condition. Under some of the eight rubries, especially numbers $134,136,137,138$, and 139 , there are probably recorded a not inconsiderable number of deaths of women before the fifth month of pregnancy. Accidents of pregnancy (134) includes accidental abortions, misearriages, extra-uterine pregnancy, and vomiting of pregnancy; puerperal hemorrhage (135) may be fatal at any period of prégnancy. Some deaths due to deformities .

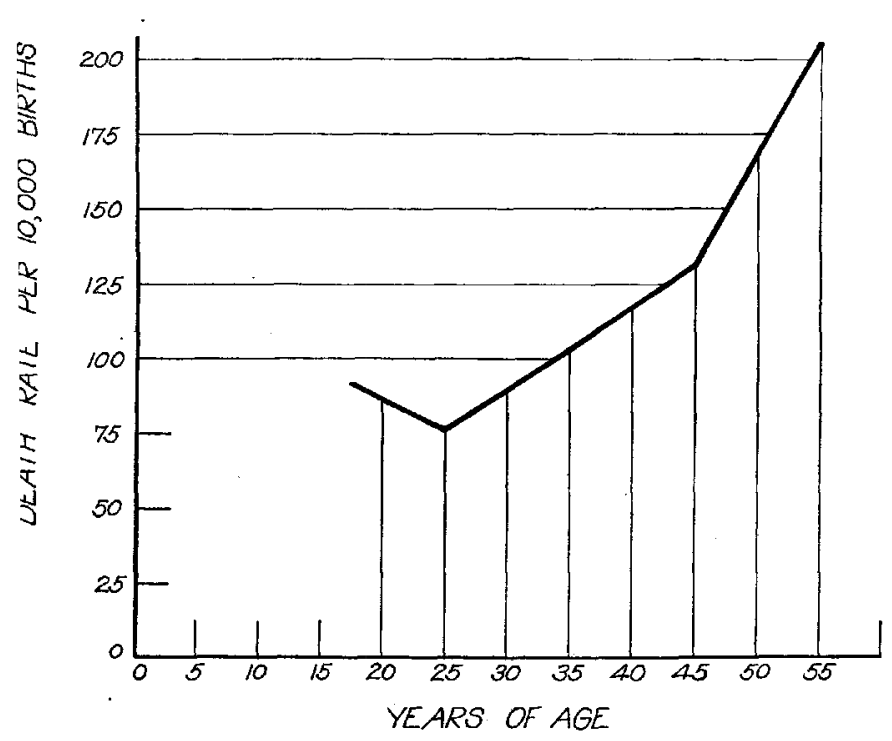

GRAPH I illustrating death rate of mothers per 10,00 births, in reference to age.

of. mother or child, to injuries and operations (136), and to puerperal infection (137) undoubtedly occur before the fifth month of pregnancy, and the same may be said of the toxemias, including renal 
affections and convulsions (138). Any of the various conditions enumerated under 139 may occur after abortions and miscarriages. The last two rubries include but a small proportion, of the total fatalities. Hence, the total number of deaths officially classified under the puerperal state (rubries 134 to 139) represents not accurately, but only approximately, the number of deaths from these causes, of women five months pregnant and over.

Therefore, in both divisor and dividend, there are minor errors for which adequate allowances for correction cannot be made under the conditions by which the data are collected and recorded. It is equally clear, however, that the method here employed should measure much more accurately than any hitherto used the risk-rate to women five months pregnant and over of dying from causes connected with childbearing.

The field being cleared in the foregoing historical review and the detailed exposition of the factors involved presented, the application of the proposed method to the analysis of the data from various sources will be undertaken.

RISK-RATE OF CHILDBEARING IN THE BIRTH REgISTRATION AREA OF THE

$$
\text { UNITED States. }
$$

Since it furnishes a material larger in size and more homogeneous in character than any other available, the birth registration area of the United States for 1918 will be considered first. This area comprises the District of Columbia and the following states: Connecticut, Indiana, Kansas, Kentucky, Maine, Maryland, Massachusetts, Michigan, Minnesota, New Hampshire, New York, North Carolina, Ohio, Pennsylvania, Rhode Island, Utah, Vermont, Virginia, Washington, and Wisconsin. It is estimated that this area contains 53 per cent. of the population of the United States. In it are situated besides the great cities of the Atlantic const and of the Great Iakes region (excluding Chicago, however), the great number of smaller cities of New England, New York, Pennsylvania, Ohio, Kentucky, and of some of the western states. Classed as "cities" are those places of 10,000 inhabitants or more, according to the census of 1910. Since there were many changes in the eight years which elapsed, the distinction between urban and rural population is not so exact as would be desirable. The rural population, therefore, is by no means so truly rural-that is, village and farm dwelling-as, this term is usually taken to imply. The frankly rural portion of the popnlation dwells 
under very widely varying conditions of density, of elimate, and of economic status, and, as is well known, it is certainly not homogeneous as to race stock. There is also, on the whole, but relatively little uniformity of the urban population in these and other important particulars. In regard to both urban and rural populations there is the greatest diversity in the character of obstetrical care. The total number of births, 1,412,283, for the area under consideration in 1918 is almost equally divided between urban and rural communities.

The figures for the maternal deaths are taken from the Mortality Statistics of the Bureau of the Census for 1918. To the possible criticism that during this year the number of maternal deaths was seriously influeneed by the great epidemic of influenza, it may be said that, both in theory and in practice, this factor is eliminated in the classification of the deaths by the Bureau of the Census. The tables for New York, Philadelphia, and Baltimore to be presented later clearly indicate, so far as the official classification shows, that influenza did not affect the number of deaths from causes connected with childbirth. At any rate, ehoice here is limited by necessity.

The results of the analysis of the whole birth registration area are set forth in Table V. The death rates, whether viewed in comparison with the rates for England and Wales or considered alone, are appallingly high for total deaths and for deaths under each important eategory. These rates, although calculated by a method more favorable than that used in comparative tables in which stillbirths are not taken into account, are probably unparalleled in modern times in a civilized country. To match the rate for the whole puerperal state ( 88.48 per 10,000 births), it is necessary to revert to the Swedish rate for $1806-1810$ ( 89 per 10,000 births). It is more than double the Swedish rate for 1851-1855, 75 per cent. greater than the average rate for England and Wales for 1847 to 1876 (50 per 10,000 living births), and 120 per cent. greater than the average rate for the latter area for 1911-1915 (40.31 per 10,000 living births), though the rate for the United States birth registration area-in which an allowance of 3.44 per cent. is made for stillbirths-is calculated on terms more favorable than that for England and Wales.

Considering first the rates for the United States birth registration area as a whole, it is evident that the risk to mothers in childbirth is excessive not only from all causes (88.48 per 10,000 deliveries, or 1 in 113), but from nearly every one of the separate causes. The rate for puerperal fever is 24.59 per 10,000 or 1 in every 407 deliveries, and for 
WILLIAM TRAVIS HOWARD, JR.

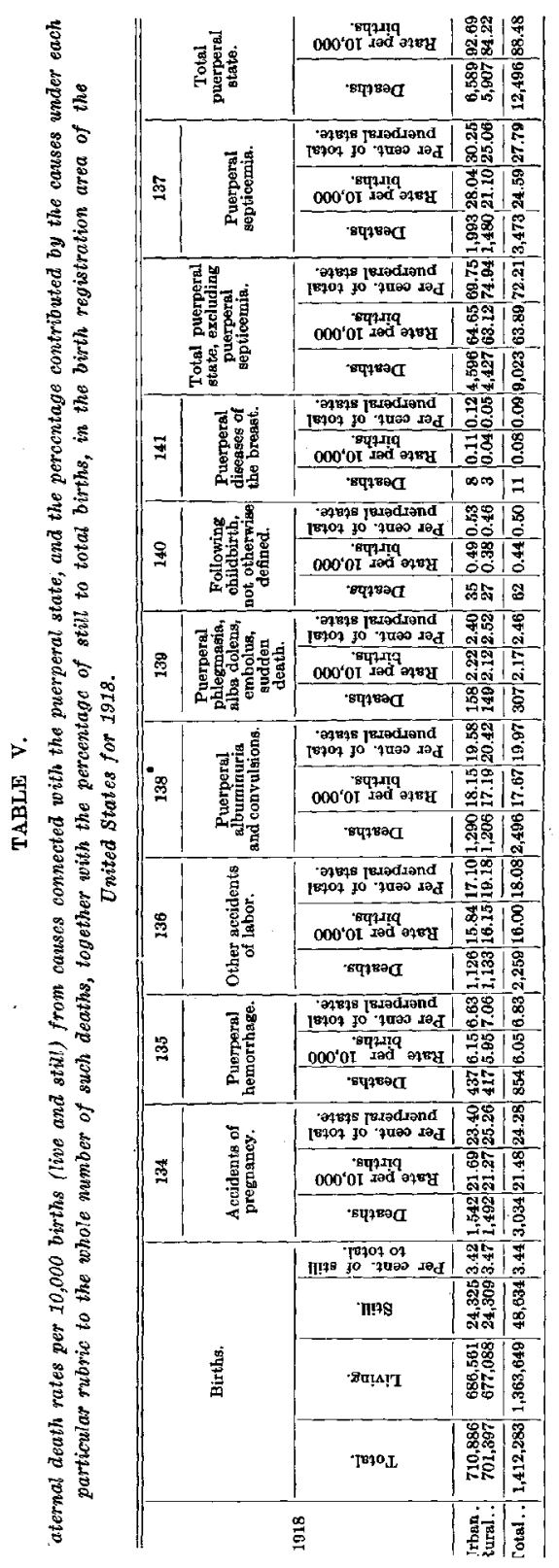


all other causes combined, 63.89 per 10,000 , or 1 in every 156 deliveries. Of all the women delivered, there dies 1 in 565 of puerperal albuminuria and eclampsia, 1 in 411 of accidents of pregnancy, and 1 in 625 of accidents of labor. The various prominent causes stand in proportion of their relation to the whole number of childbed deaths as follows.

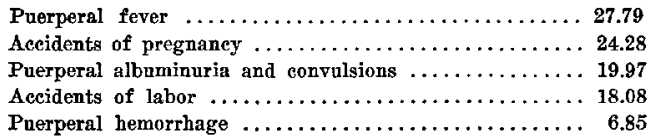

The other causes are of comparatively slight importanee.

To return to the comparison with England and Wales, in order to form a correct idea of the facts disclosed by this analysis, the rates in the birth registration area of the United States exceed the rates in England and Wales (see Table III) by nearly 75 per cent. for puerperal fever and 150 per cent. for the other affections of the puerperal state combined. In the important categories of the latter group, accidents of pregnancy and labor, the rates for the United States birth registration area as compared with the English rates are greater by over five times for the former and nearly four times for the latter. There is but little difference between the rates in the two countries for puerperal hemorrhage. Puerperal fever is responsible for 27.79 per cent. of the whole number of deaths in the puerperal state in the United States birth registration area and for 35.24 per cent. in the English, while all other eauses in the puerperal state cover 72.21 per cent. in the former and 64.75 per cent. in the latter. (See Tables III and V.)

It will be noted that for the birth registration area of the United States, the total rate and the rate for puerperal septicemia are considerably lower in the rural than in the urban communities, while the rates for the other separate categories are approximately the same; therefore, it would appear that the more favorable rural total rate is due ehiefly to the marked difference in the proportion of deaths from puerperal septicemia in rural as compared with urban districts. These urban rates for the birth registration area are considerably higher in each category than the corresponding rates for the large eastern medical centres, New York, Philadelphia, Boston, and Baltimore. (See Tables X, XI, XII, and XIII.) This difference is very 


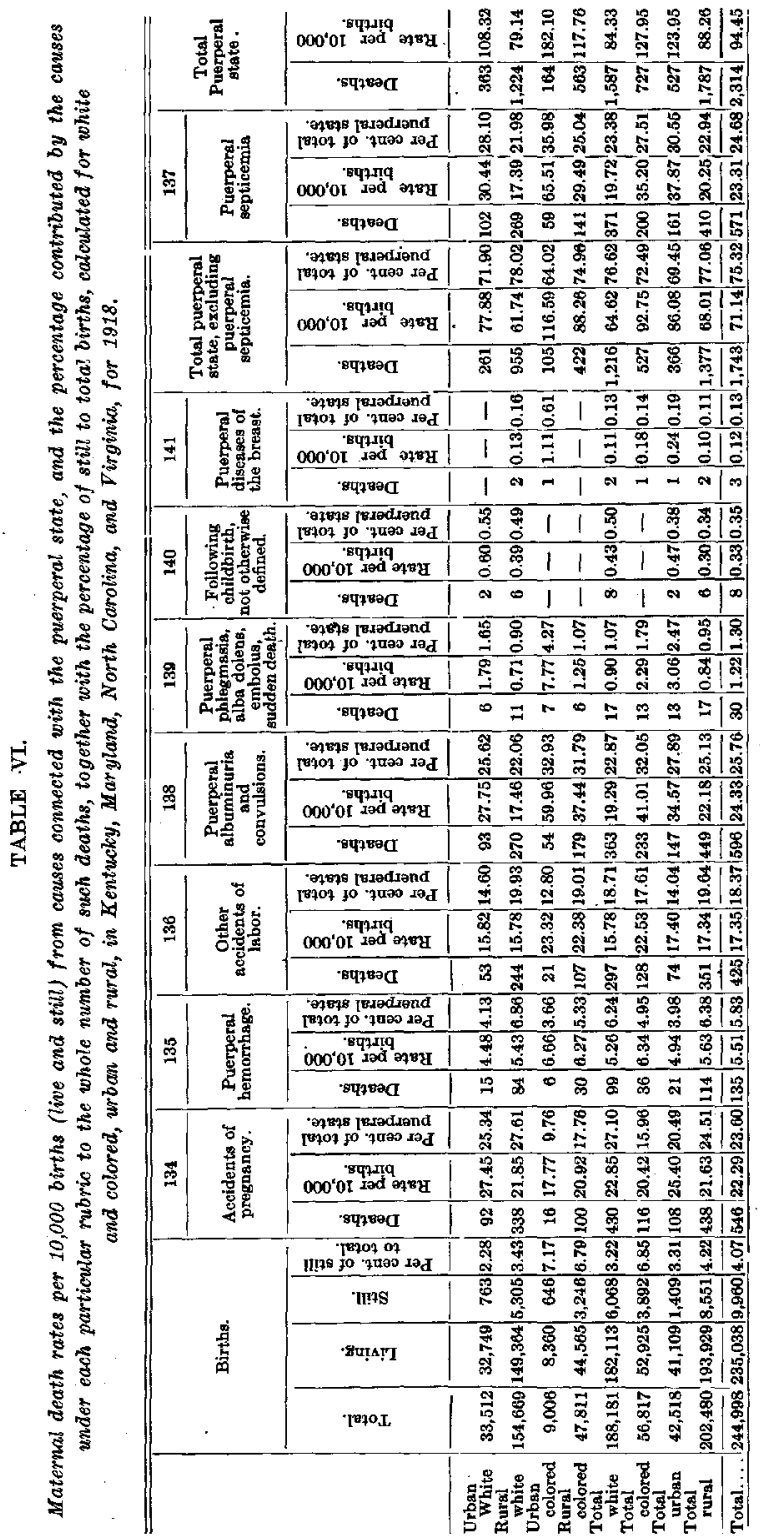


likely due in part to poorer obstetrical care in the large cities of the interior and in the smaller cities throughout the territory included in the registration area.

Since the figures for the still and live births and for the maternal deaths in the puerperal state are tabulated for white and colored in the registration states of Kentucky, Maryland, North Carolina, and Virginia, it is possible to determine the difference in the force of mortality in childbirth in white and colored women under both urban and rural conditions. The results of the calculations are shown in Table VI. Because there are but few Mongolian and Indian females in the populations of these states, the term colored may for all practical purposes be taken to express women of negro or partly negro stock. Since the chief purpose of the comparison is to investigate influenees of race stock upon childbirth mortality, negro is used in these remarks instead of the official word colored. Though in the area now under consideration the urban population numbers somewhat less than one fifth of the rural, nevertheless the sample of the former is of considerable size and includes Baltimore, Richmond, and Louisville, comparatively large cities with conspieuously large negro populations. In the four states, the total rate and the urban and rural rates for all causes connected with the puerperal state are considerably in excess of those of the whole registration area. The rates for total deaths stand in order of their favorableness: white rural, total white, white urban, colored rural, total colored, colored urban. For puerperal septicemia, the total and the total rural and the rural white and the total white compare favorably with those for the registration area as a whole $(23.31,20.25,17.39$, and 19.72 , respectively, to 24.59$)$. The differences in the ratio for this cause between urban and rural rates for total, white, and colored, and particularly for the latter, is marked. The total colored is nearly double that of the total white. For the total puerperal state, puerperal fever excluded, the total rate and the urban and rural rates all are higher than those for the whole registration area. The urban rate is always higher than the rural, and the colored rate, than the white. While the accidents of pregnancy show a higher rate in the white than in the negro, the reverse is true for accidents of labor-a set of causes more particularly associated with deformities and with delivery. Puerperal hemorrhage is in none of the groups a conspicuous cause of death, the average being 5.83 per cent. of the total deaths. It is less fatal in the city dwellers than in the rural dwellers of both white and negro races, 
and in the white, less fatal for the former than for the latter community. Other accidents of labor, causing over 18 per cent. of the total deaths, has approximately identical rates for city and country in both races, but is greater by a third for negroes than for whites. Puerperal albuminuria and convulsions, responsible for 25.76 per cent. of the deaths and markedly higher in the urban than in the rural population for both races, is twice as fatal for the negro as for the white woman. The other two categories of causes play parts too minor to make them of serious aceount.

In these four states, in which the Anglo-Saxon stock greatly preponderates among those of white blood, and notwithstanding the relatively favorable influence exerted by the lower rate among the whites in Baltimore (62.02 per 10,000 deliveries), the death rate in childbearing $(84.33$ per 10,000$)$, though somewhat lower than in the registration area as a whole $(88.48 \mathrm{per} 10,000)$, is markedly higher than any recorded for England and Wales since 1842 and nearly twice that of Sweden in 1855 . The total rate for negroes (127.95 per $10,000)$ is considerably higher than the same rate in Baltimore. (109.54 per 10,000$)$, and the urban rate $(182.10$ per 10,000$)$ is 55 per cent. greater than the rural rate $(117.76$ per 10,000 .) The urban rate is nearly 2 per 100 , or about 1 in 45 deliveries, while in the country 1 out of about every 58 childbearings is fatal to the mother. Since the proportion of stillborn is so high among the negroes, the sacrifice of mothers in producing live children is even greater than these figures indicate. Though further and more intensive studies based upon accurate and complete histories of a sufficient number of cases are necessary to determine definitely the reasons for the greatly higher maternal mortality in the negro over the white in childbearing, the evidence at hand suggests that the causes at work are concerned in considerable degree, at least, with difference in degree of racial susceptibility to puerperal infection, albuminuria and convulsions (the toxemias of pregnancy and eclampsia), and to accidents of labor. The rates of Table VI show that, whether in city or in country, the mortality from these causes is much in excess among the negroes.

\section{INFLUENCE OF AGE UPON RISK-RATE OF CHILDBEARING IN THE BIRTH Registration area of the UNited States.}

In Table VII, the births and the maternal deaths by age periods and the rates calculable therefrom are given for the birth registration 


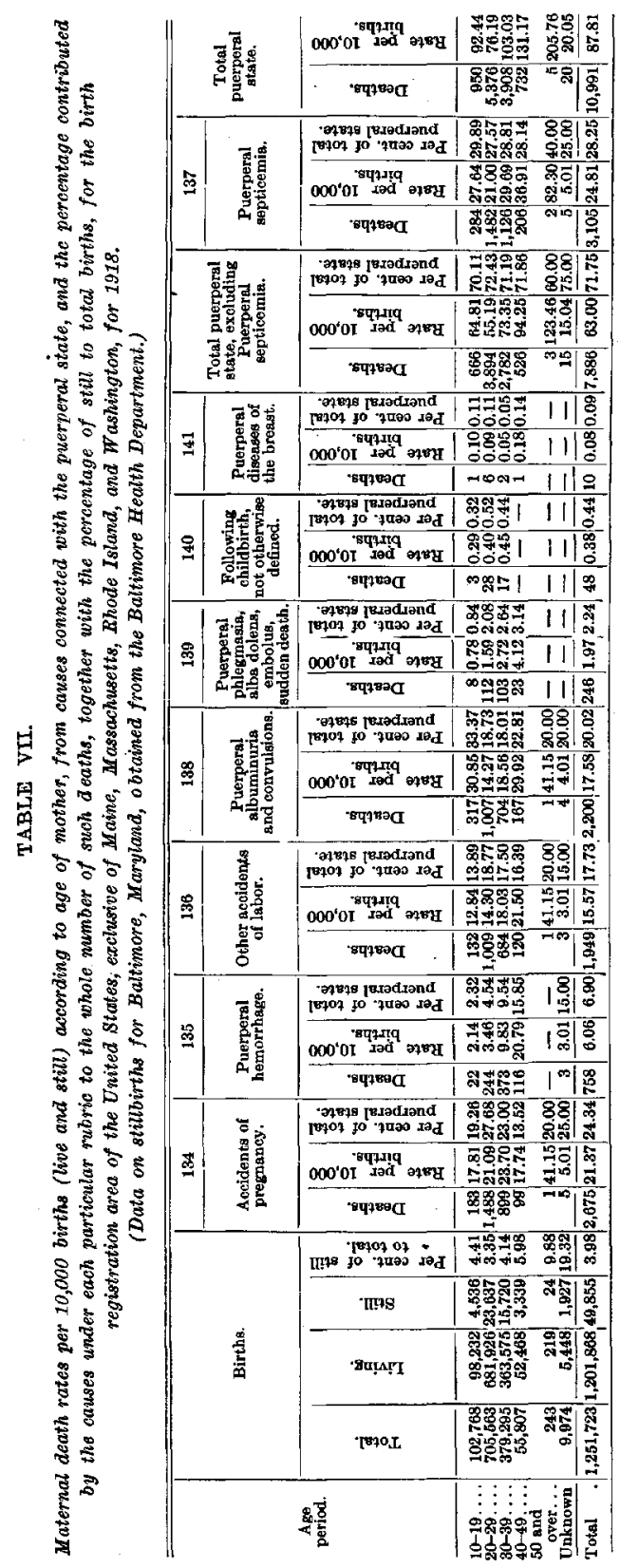


area as of 1918, with the omission of eertain states-Maine, Massachusetts, Rhode Island, and Washington, for which comparative data could not be obtained. On account of the manner of age classification of deaths in the Mortality Reports of the Bureau of the Census, it is not possible to begin in the ten year periods with the fifteenth year as in Farr's Table.

It will be noted that for the first age group, 10 to 19 years, in which abont one twelfth of the births oceur, the total rate is higher than for the second ten year period, 20 to 29 years, but lower than for any other of the age divisions. The maternal death rates in this group, in which most of the labors probably occur in primiparae, are, in comparison with the second and third age groups, relatively low for all the important eategories embraced under "total puerperal state, excluding puerperal fever," with the exception of the one category-albuminuria and convulsions. The rate for puerperal fever and the total rate are higher, and the rates for aceidents of pregnancy and labor and for hemorrhage are lower than for the averages of all ages.

The second age group, in which over half of the labors fall, shows the lowest rates for total and for the important rubrics of septicemia and albuminuria and convulsions, and, in contrast to the succeeding age groups, in the rate for accidents of labor; for this category, as with all the other important ones, it is below that of the average for all ages. So far as can be determined by this method of age classification, this is, on the whole, the most favorbale age for childbearing.

The third and fourth age groups, 30 to 39 years and 40 to 49 years, including over a third of the labors, show in most of the eategories progressively higher rates-the increase of the risk of death from hemorrhage, albuminuria and convulsions, and puerperal fever being conspicuous at these higher ages. The total rates are in consequence higher than at other ages.

The age group "over 50 years," with high rates in all the important categories, particularly in septicemia, has a total rate of 206.68 per 10,000 . The sample, however, is too small to warrant fast eonelusions.

The relative importance in the various age groups of the different categories is shown in the columns of percentages. The value of these from the practical standpoint of prognosis would be considerably enhanced, if it were possible to make the age groupings by quinquenmial periods. The influence of the age of the mother upon the 
death rates from all causes connected with the puerperal state is indicated in Graph I (p. 207).

The risk-rate of childbearing in certain cItTES OF Europe and THE UNIted States.

In the annual reports of European cities, which so far I have been able to obtain, there are only two, Stoekholm, Sweden, and Birmingham, England, in which the stillbirths are reported and the maternal deaths are given under the separate rubrics over a series of years. For comparison with similar data for the below mentioned eities of the United States, I have compiled tables for these eities, showing the total rates and the rates for the different eategories under deaths in the puerperal state. The data for these cities and for New York, Philadelphia, Boston, and Baltimore were obtained from the aunual official health reports. Therefore, since the deaths were not classified in the Bureau of the Census, there may be some difference in their assignment in some of the categories, due to variations in enstom or of opinion in the several statistical bureaus.

It will be observed that the classification used in Stockholm is somewhat different from that of the international classification and with fewer rubrics. Apparently, however, the latter include all the deaths occurring in the puerperal state (see Table VIII). Had the table for Stockholm been made to include the years 1910 to 1914, the showing for the city wonld have been even more favorable. Indeed, when the steady upward progress of the rates for puerperal septicemia since 1914, causing a doubling of the rate for that eategory and a large increase in the total rate, is taken into consideration, it would appear that during the World War factors favorable for this affection have been active in Stockholm, temporarily affecting the rates to a disadvantage. Hemorrhage, except from placenta previa, is probably included under "other accidents of labor." The rates for the total puerperal state are remarkably low. The unusually excellent results in the management of labor in Stockholm are probably explained partly by the physique of the women and partly by good obstetrical practice and the large extent to which hospitalization is exercised. The low pereentage of stillbirths to total births supports this view.

The death rates for the puerperal state for Birmingham are probably among the lowest reached by any large eity and are the result of efforts intelligently directed over a long series of years (see 


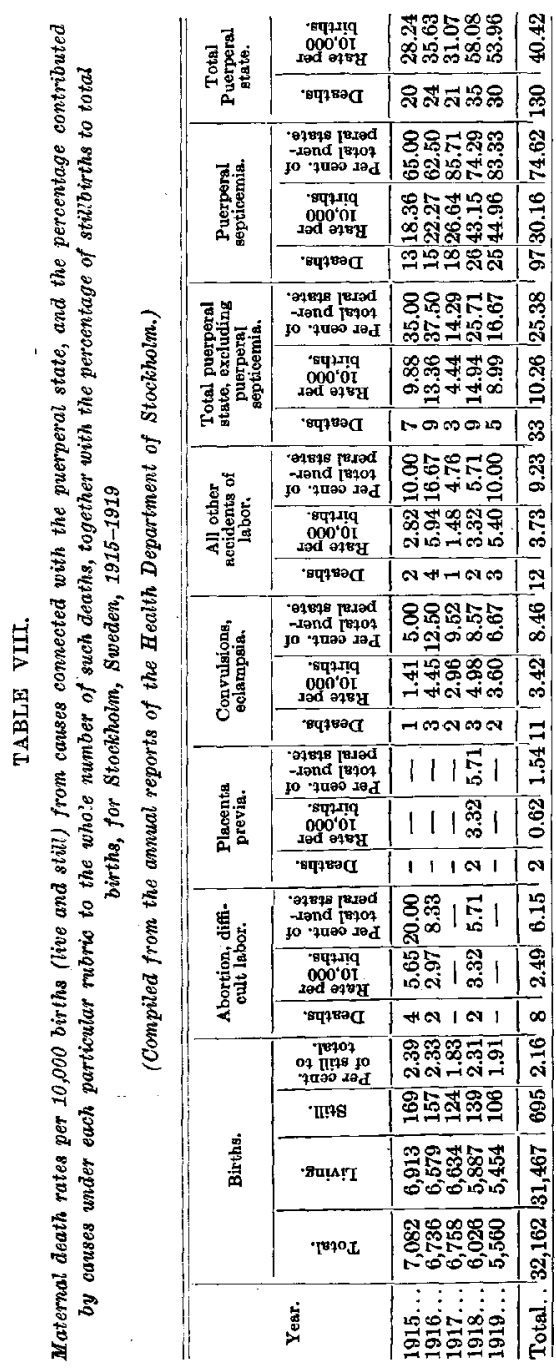




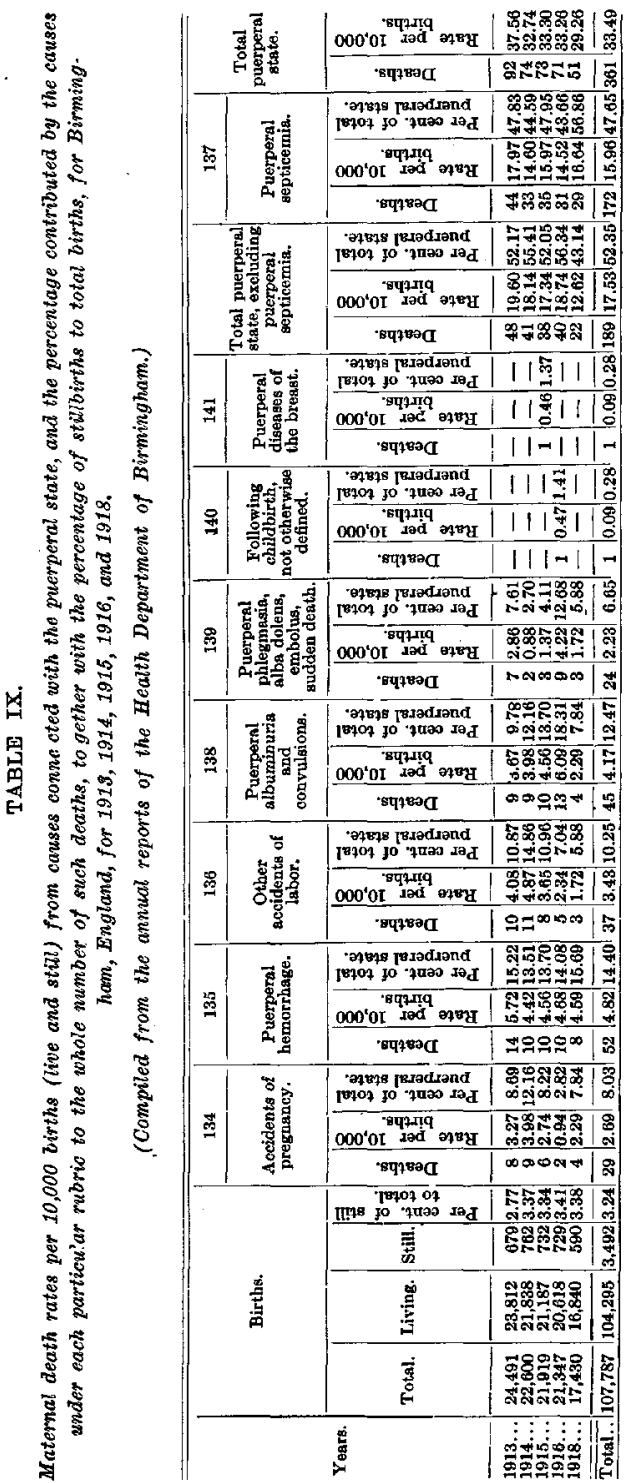


Table IX.) It will be noted that the total rate has consistently fallen throngh the five-year period, three and one half years of which were during the World War. The rate for each of the important categories is strikingly low. It is evident, when comparison is made with the rates of New York, Philadelphia, Boston, and Baltimore, and with those of the birth registration area of the United States, that the low rates of this manufacturing city must, in large degree, be due to the character of obstetrical care afforded. These rates are not only so low, but relatively so well balanced, that they will be taken as standards of comparison for the American cities now to be diseussed.

The average total rate for New York City (46.11 per 10,000 labors), conspicuously lower than that for any of the other cities of the United States under consideration, is over 35 per cent. higher than that for Birmingham (see Table $\mathbf{X}$ ). The average rate for puerperal septicemia is not only lower than that for Birmingham, but the rate for this affection has fallen continuously throughout the five year period, and in 1919 reached the remarkably low figure of 11.41 per 10,000 labors. The reports of the Department of Health indicate that this result has been materially influenced by persistent and intelligently directed administrative measures. While the rates for the other categories are not so low as those for Birmingham, they are well below those for the other American cities in this group.

In Philadelphia, both the total rate (61.48 per 10,000 labors) and the rates for the important categories are well above those for New York-notably so for puerperal fever, the average rate (27.10 per 10,000 labors) being double that (14.41 per 10,000 labors) for the latter eity (see Table XI). In accidents of labor, however, the record of Philadelphia is lower by half, but this is evidently due to classifying deaths under 140 which in New York would be assigned to 136 .

The rates for Boston, for 1914 to 1918 , are given in Table XII. The average rate for all causes connected with the puerperal state (70.71 per 10,000, or 1 in 141 births) is excessively high as eompared with the other eities. The average rates for all the important rubrics are considerably higher than in New York, and with the exception of puerperal septicemia they are greater than those in Philadelphia. In regard to puerperal septicemia, Boston surpasses Baltimore, in spite of the large negro population of the latter city.

The average total rate for the puerperal state in Baltimore is not only very high (64.89 per 10,000 , or about 1 in every 150 deliveries), 


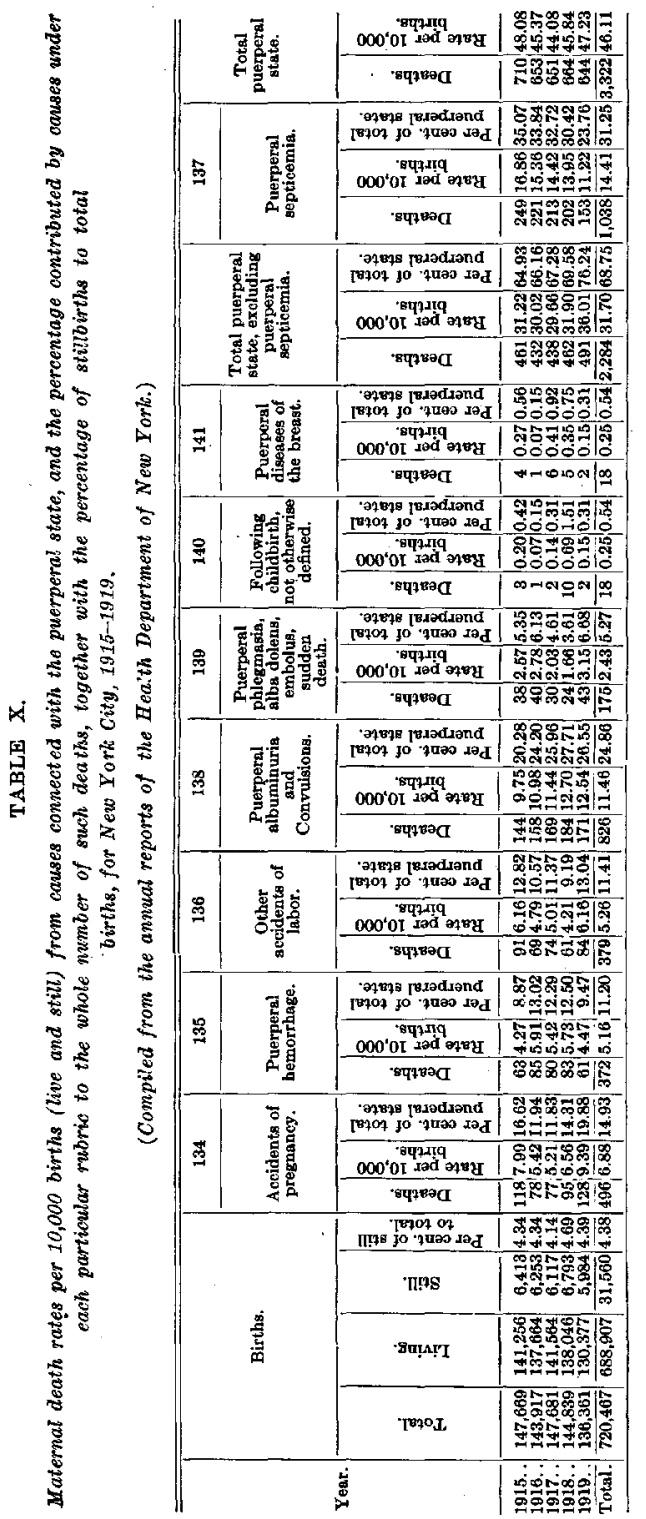




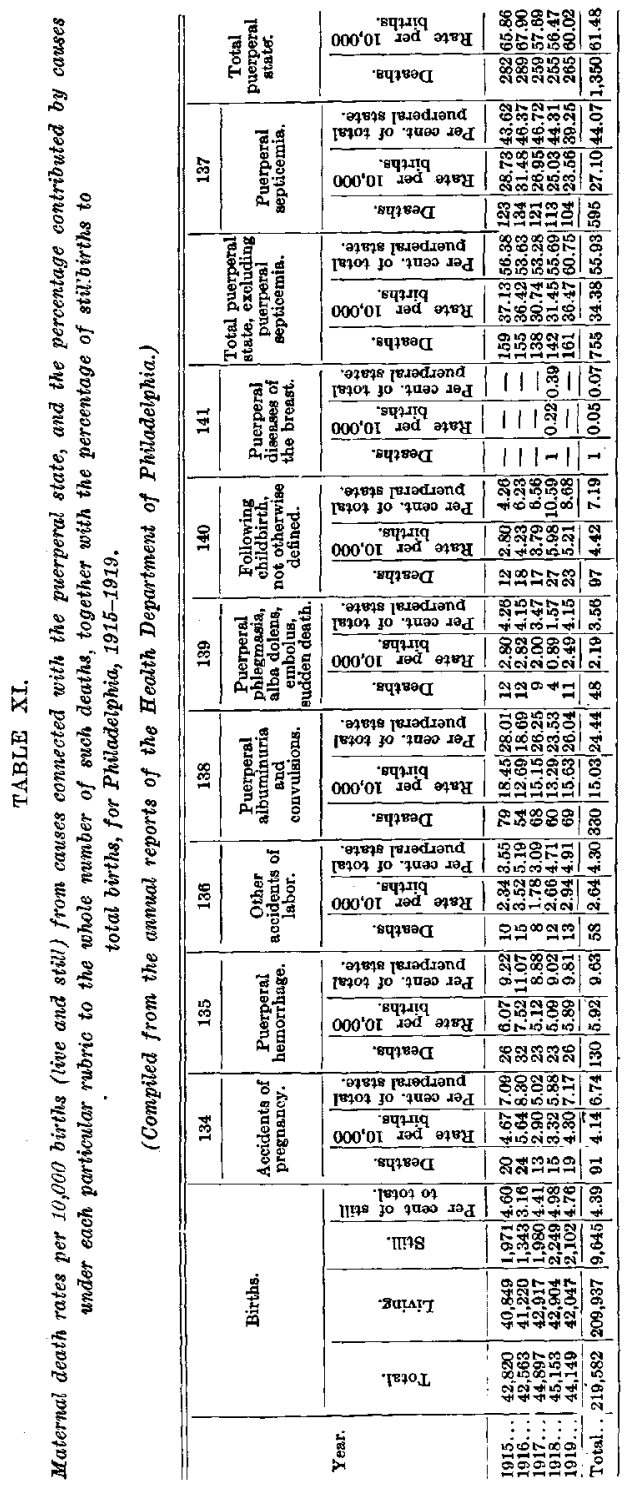




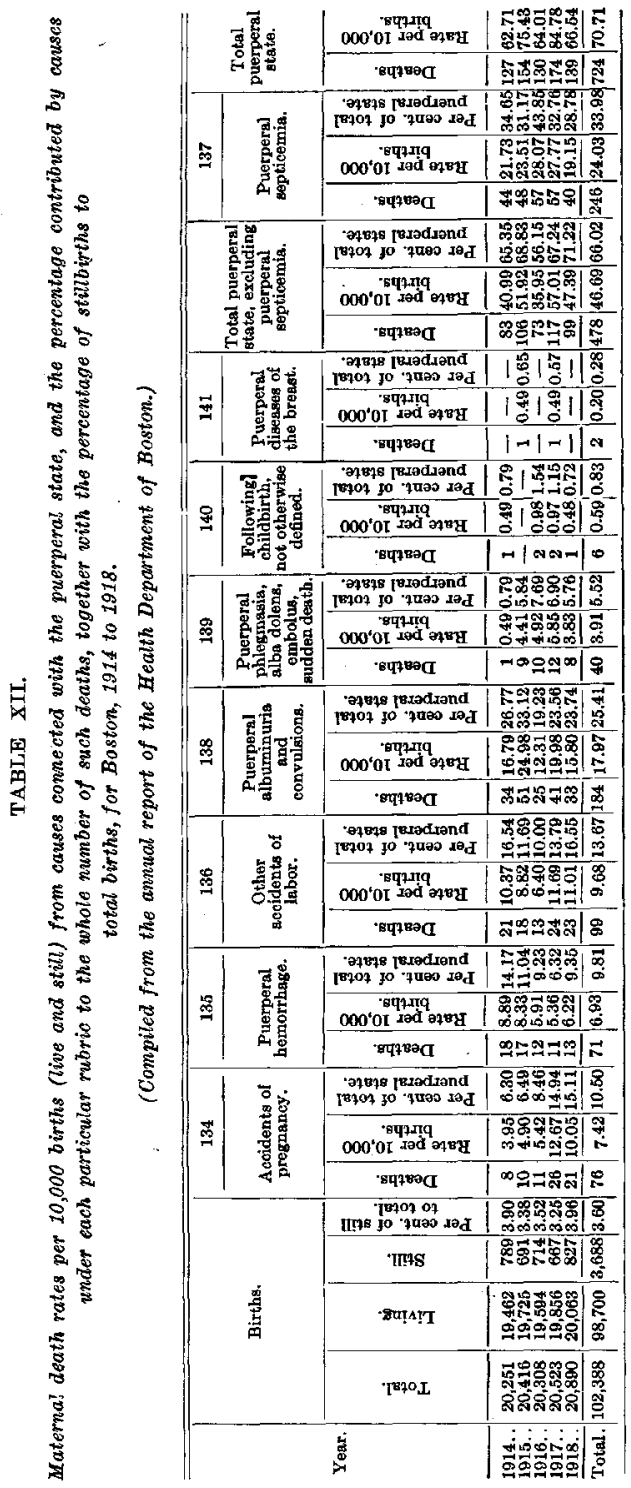


but unlike those of New York and Philadelphia shows an tmost unbroken ascent and in 1919 is almost 40 per cent. higher than in 1915. This increase is in nearly every rubric, including septicemia. The average rate for the latter affection, however, is conspicuously lower than that for Philadelphia and for the birth registration area, but much higher than that for New York (see Table XIII). On the whole, the record for Baltimore, like that for Boston, is without a redeeming feature, even the rate for puerperal hemorrhage being about 40 per cent. above the average for that category in the other tables. On account of the large size of the negro population, Baltimore offers a good opportunity to compare the childbed death rates among negroes and whites in a large city. Negroes comprise about 2 per cent. of the populations in New York and Boston, and about 5 per cent. in Philadelphia. In Baltimore, about 15 per cent. or one sixth of both population and births, is negro. The two years, 1916 and 1919 , for which data for comparison are obtainable, are by chance the years showing the lowest and the highest rates. It will be noted that the average of the total negro rate for these two years is almost double that of the white (109.54 to 62.02), the cause of the excess being the higher negro rates for aecidents of labor, puerperal convulsions and albuminuria, and septicemia, all of which are extraordinarily high and double those of the whites ( 1 in 90 as against 1 in 160 deliveries). The rate for puerperal septicemia (40.44 per 10,000 births) in the negroes in Baltimore is higher than the total rate for the whole puerperal state in Birmingham and Stockholm, and not far from that in New York. It is interesting that the comparatively high rates for accidents of pregnaney and for puerperal hemorrhage in Baltimore are approximately the same for the two races.

According to information furnished me in 1917, about one half of the lying-in women receiving obstetrical care in the well organized in- and out-patient departments of the obstetrieal elinies of the Johns Hopkins Hospital and of the University of Maryland Hospital are negroes, representing about 50 per cent. of the annual number of negro births in the city. The other half of the deliveries in these obstetrical services includes less than 10 per cent. of the white births. The deliveries in these institutions represent approsimately 15 per cent. of the annual births in the City, so about 50 per cent. of the negro and about 10 per cent. of the white labors occur under these auspices. Notwithstanding these relatively very favorable opportuni- 
THE REAL RISK-RATE OF DEATH TO MOTHERS.

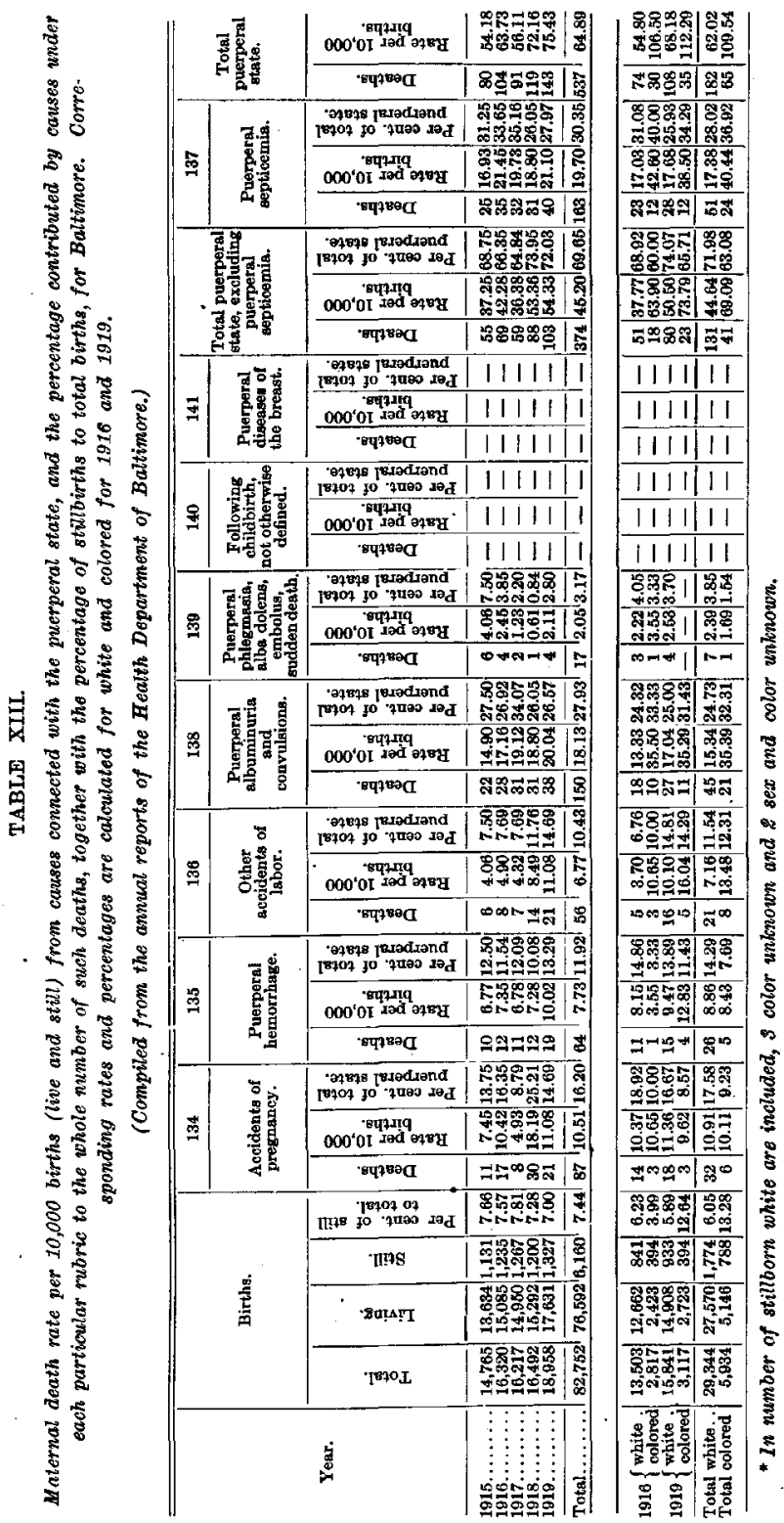


ties for lying-in care, the Baltimore negress is a very poor maternity risk. Her chances are materially better, however, than in the four states analyzed in Table VI.

In this connection, comparison may be made with Washington, D. C., rates for which I have calculated for 1918 on the basis of figures from the census reports. With 8,673 births (living and still), 6,298 white and 2,375 colored, and 74 maternal deaths, 47 white and 27 colored, the total maternal death rate was 85.32 per 10,000 births -74.63 for white and 113.68 for colored. Thus, in the National Capital, the risk rate for ehildbirth for the negro exceeded that in Baltimore.

\section{STILLBIRThS.}

The question of the relative frequency of stillbirths as compared with live births is one of great interest and importance. That the proportion varies in the same country at different times and places and in different countries is to be expected. Owing to uncertainties as to what the term stillbirth is used to comprehend at different times and in various loealities, absolute comparisons are unwarranted and minute corrections are impossible.

For the sake of comparison, figures for Sweden and other continental countries taken from the tables of Hendriks (loc. cit., p. 167) and figures from my tables $V$ to XIII are given in Table XIV. In regard to Sweden, Hendriks showed that from 1776 to 1855 , on an average to every 100 deliveries there were born 101.62 live and still born children, of which 98.80 were live and 2.80 still born; during the five year period, 1851 to 1855 , these proportions were in the rural districts $101.39,98.27,3.12$, and in towns, $101.46,96.98$, and 4.48 .

It will be noted that the percentage of stillbirths for Sweden was much lower than in any of the other countries given in Hendriks table and that the percentage in Stockholm is at the present time considerably below that of any of the other cities in my table. In comparison with the experience of Swedish towns in 1851 to 1855, the stillbirth percentage of this city is now lower by one half. This relatively low pereentage of stillbirths in Sweden and its chief city is probably influenced by the same factors already suggested as explaining the low death rates in maternity; i.e., the physique of the women and the superior obstetrical care. However, that low maternal death rates and low percentages of stillbirths do not of necessity 
go together is evident from the figures of Birmingham, New York, and Boston. The former eity with its remarkably low maternity death rates has a stillbirth rate nearly as high as that of Boston, where the maternity death rates are notably high. Philadelphia, with a maternity death rate greater by more than 30 per cent. than that of New York, has the same stillbirth rate. In the birth registration area as a whole and in the four states, Kentucky, Maryland, North Carolina, and Virginia, taken together, with maternity death

TABLE IV.

\begin{tabular}{|c|c|c|c|c|c|}
\hline \multicolumn{3}{|c|}{ Hendriks. } & \multicolumn{3}{|c|}{ Howard. } \\
\hline City or country. & Date. & $\begin{array}{c}\text { Average } \\
\text { percentage } \\
\text { of gtill to } \\
\text { total births. }\end{array}$ & City or country & Date. & $\begin{array}{c}\text { Average } \\
\text { peroentage } \\
\text { of still to } \\
\text { total births. }\end{array}$ \\
\hline 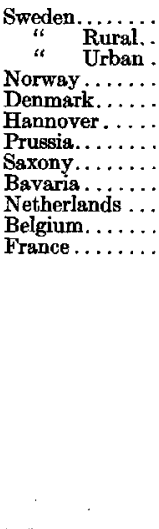 & \begin{tabular}{|l|}
$1776-1855$ \\
$1851-1855$ \\
$1851-1855$ \\
$1836-1845$ \\
$1845-1849$ \\
1853 \\
$1825-1849$ \\
$1847-1849$ \\
$1844-1851$ \\
$1848-1853$ \\
$1841-1850$ \\
$185 \mathrm{I}-1854$
\end{tabular} & $\begin{array}{l}2.77 \\
3.12 \\
4.48 \\
4.08 \\
4.26 \\
3.87 \\
3.69 \\
4.49 \\
3.3 \\
4.97 \\
4.18 \\
3.79\end{array}$ & 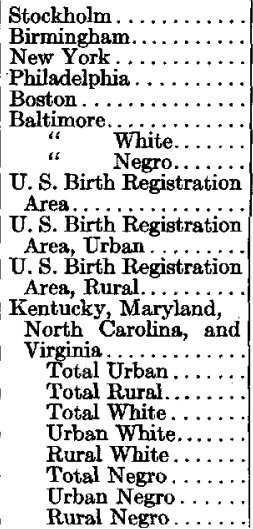 & \begin{tabular}{|c|}
$1915-1919$ \\
$1913-1918$ \\
$1915-1919$ \\
$1915-1919$ \\
$1917-1918$ \\
$1915-1919$ \\
$"$ \\
4 \\
1918 \\
4 \\
$"$
\end{tabular} & \begin{tabular}{|r|}
2.16 \\
3.24 \\
4.38 \\
4.39 \\
3.60 \\
7.44 \\
6.05 \\
13.28 \\
\\
3.44 \\
\\
3.42 \\
\\
3.47 \\
\\
\\
4.07 \\
3.31 \\
4.22 \\
3.22 \\
2.28 \\
3.43 \\
6.85 \\
7.17 \\
6.79
\end{tabular} \\
\hline
\end{tabular}

rates much higher than that for New York, the stillbirth rates, whether total, urban or rural are considerably lower than in that eity. The stillbirth rate for the whole birth registration area of the United States is but very little higher than that of Birmingham, whose maternal death rate is, on the other hand, less by considerably more than 60 per cent." The very high stillbirth rate of Baltimore,

* The explazation of this seeming paradox must be sought for in the operation of some potent cause of maternal death, which is at the same time without 
in both white and negro is due to some degree to the eustom of reporting as stillbirths fetuses of earlier months of utero-gestation, partly under the influence of the state authorities and partly because of the response of physicians to requests for stillborn fetuses for scientific investigation in the laboratories of embryology. It is probably not far from the truth to assume that on the same basis of birth reporting in other places, the percentage of still to total births in Baltimore is not far from 5 in whites and 11 in negroes-rates of fetal fatality of considerable eminence. The percentage of stillbirths to total births in Washington, D. C., for 1918, was 5.89 for the whole number, 4.40 for white, and 9.85 for negro. It is significant that here as in the four states, Kentucky, Maryland, North Carolina, and Virginia, the stillbirth rate for negroes is double that for whites. In this division of the registration area, the stillbirth rate for whites is lower in the eities than in the rural districts, while for negroes, the opposite is the case.

It has long been known that fetal fatality is infuenced conspicuously by causes inherent in the fetas itself (namely, errors of implantation and of development) and by accidents in utero-malposition of fetus and of cord, as well as by infectious diseases of the mother or of the fetus, or of both (such as, smallpox, pneumonia, typhoid and typhus fevers, influenza, and syphilis), by deformities and various toxemias and chronic diseases of the mother, and by injuries and accidents in pregnancy and labor.

From the material now under consideration, it is not possible, of course, to determine the relative importance of these various causes of stillbirth. It is well established that the effects of many of these causes may be modified or even completely controlled by appropriate care during pregnancy and Iabor. Hence, to a considerable degree, the proportion of stillbirths to live births in a community may be used as an indicator of the eharacter of obstetrical care obtained by pregnant and lying-in women. When both the maternal and fetal death rates are high, unless the race stock is particularly weak, poor obstetrical care may be assumed. When the maternal death rate is comparatively low and the stillbirth rate is high, and vice versa, it may be predicated that obstetrical care is good but inadequately balanced. When the death rates for both mother and fetus are low, efficient and well rounded obstetrical care is indicated.

influence upon infant mortality. This is found in puerperal septicemia, the one prominent cause of maternal deaths from causes connected with the puerperal state that does not ordinarily act or begin to act until some days after labor. 
Caushs of high maternal death rates and high stullbirth rates IN THE UNITED STATES, AND THEIR CORRECTION.

Abundant experience teaches that high maternal and infantile death rates from causes connected with childbearing are associated with inadequate care afforded by ignorant and careless accouchers and nurses and that, conversely, low death rates obtain in the practice of well-trained and careful attendants, even under environmental conditions ordinarily considered adverse. It is known that physicians and midwives of certain levels of intelligence and education can be trained to become accomplished accoucheurs. It is equally well known that in the United States, until very reeent years, diploma mills ground out some intelligent and numbers of nnintelligent and poorly trained men and women physicians with hopelessly inadequate obstetrical training and that many of these are still in the full bloom of practice. It is no secret that there are in this country no properly organized schools for training midwives and that even where midwife practice is supposedly regulated by legal statute, registration, examination, and supervision are tragically farcical. Of all the important branches of the nursing art, that of obstetries is perhaps at once the most neglected and the most important. It cannot be questioned that the risks to both mother and child, even in the care of the most intelligent and well-trained accoucheurs, are enhanced by those constitutional weaknesses, racial or individual, inherited or aequired, general or local, that influence deformities, aceidents of pregnancy and labor, toxemias, and resistance to infection. There is considerable evidence that the negro race in the United States is in these respects constitutionally weaker and therefore a poorer ehildbirth risk than the white. To what degree this handicap is increased by poorer obstetrical care is, however, unknown, while, in the indefinite congeries of causes grouped under accidents of pregnancy in Tables VI and XIII, the rates for whites are actually higher than for negroes; in accidents of labor, puerperal albuminuria and eelampsia, and septicemia, the rates for negroes are invariably higher, and for Baltimore, there is some evidence that these differences are to a certain extent independent of the character of obstetrical care. These data are, however, inadequate for far reaching conclusions.

Why should maternal mortality rates be so much lower in the rural than in the urban communities of the United States Birth 
registration area and in Kentucky, Maryland, North Carolina, and Virgina, and yet lower in the large cities of New York, Philadelphia, Boston, and Baltimore than in the rural districts, in only one of which eities, New York, is there evidence that administrative measures have influenced that result-and there only in the one category, puerperal fever To what degree is the difference between rural and urban maternity death rates due to the carrying of the worst risks to "cities" for obstetrical care? What is the difference between the relative distribution of midwife and medical obstetrical care in urban and rural communities? Are midwives, on the whole, better and safer obstetrical attendants in the United States than physicians? Is either the average medical or midwife attendant in rural superior to those in urban communities? To what degree are the variations in the rates as ascertained influenced by the differences in the ages at which childbearing oceurs, and in the number of pregnancies per woman, in urban and rural communities? Are so-called native-born women worse or better childbed risks than foreign-born women, and if so, why, and how do the latter vary in this regard among the various immigrant stocks? Are women living in rural districts inherently better obstetrical risks than women of the same race in cities, and are the lower rates obtaining in New York, Philadelphia, and Baltimore due to superior obstetrical care operating on material even less favorable than in the rest of the birth registration area? What are the most important preventable causes of stillbirth? These are some of the many important questions demanding answers.

Prevention and control of illness and death of mother and child are among the most neglected and potentially the most fruitful domains of American public health administration, and, of the problems concerned, the two greatest are the toxemias of pregnancy (including albuminuria and eclampsia) and puerperal fever, of which, the latter is the more readily approached.

My present purpose, however, of calling attention to the importance both to public health administrators and to scientific investigators of specific morbidity and mortality rates in general, and in the puerperal state in particular, of the use of a method of greater exactness than any in common use, is sufficiently served by the material presented.

To those whose duty it is to ascertain the causes and to apply the remedies, it may with propriety be pointed out that vital statisties holds the same relation to advanees in public health knowledge and 
administration that pathological anatomy bears to the advance of fundamental knowledge in clinical medicine and surgery. In investigating the causes of death in the puerperal state, with but comparatively slight increase in work, in municipal and state health departments rates still more refined may be obtained by making subclasses under some of the rubrics-as for instance, in 134, accidents of pregnancy, certain deaths not concerned in childbirth could be eliminated. In administrative efforts directed toward reducing the mortality in the puerperal, including the pregnant, state, deaths from not only puerperal infection, but causes under all other rubrics, must be analyzed, both as to the environment and as to the obstetrical personel under which they occur in different kinds of women. It is likely that at least in the United States, the personal attendant is generally the most important factor. Those physicians and midwives who have consistently high maternal or infantile death rates would become evident, and could be dealt with appropriately. The information aequired in regard to the other eauses will suggest suitable remedies.

In all such studies, it is of the greatest importance that careful consideration should be given to race, and by race is here meant race stock and not the deceitful classification by nationality as expressed by geography. If in a large eity, the birth certificate be made to show the age of the mother and the number of previous children born live and dead, sufficient data would be accumulated in a short time to determine the relation of the number of children born, both singly and plurally, and the age of mothers to maternal and infantile mortalities. There is happily in the department of health of the city of New York evidence of a direct relation between the statistical studies in the Bureau of Records and the successful efforts toward the administrative control of puerperal fever, but in this respect New York stands in lonely isolation.

Among the Iessons diselosed in this study is the deplorable lack of proper appreciation and use of statistical methods and of inductive reasoning from data elicited thereby, in the city and state health departments of the United States birth registration area. It is almost inconceivable that a community large or small, inhabited by people of average intelligence and of relatively great wealth, would fail to apply remedies for such glaring and wholesale women murder, as the data for the United States birth registration area, properly studied, disclose. When the horror of the conditions these 
data divulge is fully appreciated, it is much to be feared that as usual, the opinions of experts, mostly self-appointed, will be followed, with effects disastrous in life and money. The methods to be followed should be based not upon mere opinions drawn from hasty assumptions snatehed from the clouds, but upon generalizations reached through induetions from adequate data analyzed, with the aid of appropriate statistical methods, by persons capable of consecutive thought.

\section{Summary.}

It has been shown in this investigation that:

1. By using the sum of the living and the still births reported and the number of the deaths of women from eauses connected with the puerperal state, rates are calculated expressing the actual risk of dying for women exposed to childbirth with a fair degree of specificity and much more accurately than those obtained by the methods in common use.

2. When this method is applied to the data for births and maternal deaths in the birth registration area of the United States for 1918, the total rate and the rates for causes under the important rubrics are conspicuously high. The total rate is more than double that for England and Wales caleulated on live births alone, and this is due to the great excess in the United States' rates for puerperal albuminuria and convulsions and septicemia, and accidents of pregnaney and labor.

3. In the birth registration area of the United States for 1918 , the total rate in urban communities was considerably greater (10 per cent.) than that in rural communities.

4. In the four states, Kentucky, Maryland, North Carolina, and Virginia, and in the cities, Washington, D. C., and Baltimore, Maryland the total rates and the rates for the most important rubries are much higher for negro than for white women, and the negro rates are markedly in excess of the whole in both city and country. The rates for both white and negro women are higher in urban than in rural communities. The excess in total rates, in relation to both race and location, is due ehiefly to higher rates for puerperal albuminuria and convulsions and septicemia.

5. As determined for the birth registration area of the United States for 1918, the age of mothers exerts a marked and progressive influence upon maternal mortality from causes connected with childbearing. 
6. As compared with Birmingham, England, and with Stockholm, Sweden, the maternal risk-rate in childbearing is much higher in New York, Philadelphia, Baltimore, Boston, and Washington, D. C., and in the order named. The total rates in these American cities are lower than the urban and rural total rates for the birth registration area of the United States for 1918.

7. The proportion of stillbirths to total births varies considerably in different places and in different races. In the birth registration area of the United States, the proportion for urban and rural communities is approximately the same, and the proportion for the negro is double that for the white, and for the urban negro somewhat greater than for the rural negro.

8. By intensive analysis of the data available in municipal and state health departments, it would be possible to determine with considerable accuracy to what degree some of the causes of high stillbirth rates and most of the causes of high maternal death rates in childbearing are due to poor obstetrical service on the part of physicians and midwives, the extent to which particular individuals are repsonsible for these fatalities, and the measures necessary to reduce them.

1. Hendetcks, Frenerick.

\section{REFERENCES.}

1862. On the vital statisties of Sweden from 1749-1855. Journal of the Statistieal Society of London, XXV, 119-174.

2. Dubirin, Lours T

1918. Mortality among women from eauses incidental to childbearing. American Journal of Obstetries and Diseases of Women and Children, LXXVIII, No. 1. 